\title{
Solidification Cracking Mechanism of Carbon Steel Weld Metal
}

\author{
The solidification cracking mechanism of weld metal for low S/P \\ carbon steels with different carbon content has been clarified
}

\author{
BY T. AMAYA, T. YONEZAWA, K. OGAWA, M. J. PELTONEN, AND H. HÄNNINEN
}

\begin{abstract}
It is well known that the solidification cracking susceptibility of carbon steel weld metal increases with increasing Sulfur (S) and Phosphorus (P) contents. However, solidification cracking was detected in the weld metal of low/medium carbon (C) steels welded by low-carbon welding wire, even in low S/P content steels, after changing the welding parameters. To clarify the mechanism of solidification cracking of the weld metal for low S/P, low/medium carbon steels welded by low-C welding wire, the effect of travel speed on solidification cracking susceptibility was studied, and the S and/or P compounds formed on the solidification cracks were identified by energy-dispersive $x$-ray spectroscopy (EDS) and Auger electron spectroscopy (AES). The solidification cracking susceptibility of the weld metal increased with increasing travel speed. The $C$ content of the weld metal also increased with the increasing travel speed, but the S/P contents did not change at any of the studied travel speeds. The $S$ compounds were detected on the solidification cracks. It was concluded that the $\mathrm{S}$ content in the remaining liquid phase in the solid-liquid region increases with increasing travel speed due to the increasing amount of the austenite phase formed during the peritectic reaction. In this way, the solidification cracking susceptibility of carbon steel increased with increasing travel speed.
\end{abstract}

\section{KEYWORDS}

- Carbon Steel • Carbon Content • Weld Solidification Cracking

- Peritectic Reaction • Travel Speed • Sulfur Compound

\section{Introduction}

To date, many papers have reported the effect of $S$ and/or P content on solidification cracking susceptibility of carbon steel weld metals. For example, Senda et al. observed that the solidification cracking susceptibility of carbon steel weld metal increased with increasing $S$ and $P$ contents while using Trans-Varestraint testing (Refs. 1, 2). Masumoto and Ozaki found that the solidification cracking susceptibility of carbon steel weld metal increased for $>0.1 \mathrm{wt}-\% \mathrm{C}$ in carbon steel due to the formation of $S$ compounds on the grain boundaries, but the influence of $\mathrm{P}$ content on solidification cracking susceptibility was low (Ref. 3). Tamaki et al. reported that the cause of solidification cracking of carbon steel weld metals was segregation of $\mathrm{P}$ and $\mathrm{S}$, as impurity elements along the grain boundaries, and that $S$ assisted the harmful effect of P (Ref. 4). Randall et al. found that solidification cracking was not observed in structural low-alloy steels containing $<0.03 \mathrm{wt}-\%$ of $\mathrm{S}$ and $\mathrm{P}$ during submerged arc welding (Ref. 5).

From these studies, it is generally agreed that the solidification cracking susceptibility of carbon steels increases with increasing $S$ and/or $P$ content, and decreases in $\mathrm{S}$ and $\mathrm{P}$ contents of carbon steel weld metals seem to prevent solidification cracking.

The present authors have used low $C$, low $S$, and P filler metal wire for welding of low/medium carbon steels with different $C$ contents for many years without observing solidification cracking. The ranges of $C$ content for low and medium carbon steels, are 0.2 wt-\% or less and 0.32 to 0.38 wt-\%, respectively. However, solidification cracking was recently observed in a weld metal using the same materials in combination with new welding parameters. In this case, the S and P contents were approximately 0.005 and 0.015 wt-\%, respectively. The $S$ and $P$ contents of these carbon steels were much lower than those of the test materials used in the earlier quoted research. Therefore, it was assumed that the detected solidification cracking was associated with specific welding parameters.

Some researchers have reported that solidification cracking susceptibility of carbon steels depends on the welding conditions (Refs. 6-8). Khallaf et al. evaluated the influence of welding parameters on solidification cracking susceptibility using a medium-carbon steel during submerged arc welding. Solidification cracking susceptibility of the weld metal decreased with decreasing welding current or increasing travel speed (Ref. 7). However, the effects of the welding parameters on solidification cracking susceptibility of the carbon 
steel weld metal with different $C$ contents has not yet been examined. Also, the identification of $S$ and/or P compounds formed along the dendrite boundaries of low $S$ and $P$ content weld metals has not been systematically examined to our knowledge.

Therefore, to clarify the mechanism of solidification cracking of low $\mathrm{S}$ and $\mathrm{P}$ carbon steels with different $C$ contents for the present study, the effect of travel speed on solidification cracking susceptibility was studied, and the $\mathrm{S}$ and/or $\mathrm{P}$ compounds formed on the fracture surfaces of the solidification cracks were identified using energy-dispersive $\mathrm{x}$-ray spectroscopy (EDS) and Auger electron spectroscopy (AES).

\section{Experimental Procedures}

\section{Test Materials, Test Coupons, Fixture Design, and Welding Conditions}

Solidification cracking susceptibility was evaluated using welding test mock-ups made of two types of test materials and a conventional welding wire with different carbon contents. The chemical compositions of a low- $C$ steel L-C, a medium- $C$ steel $\mathrm{M}-\mathrm{C}$, and a 1.4-mm-diameter welding wire (AWS A5.18/A5.18M.) are listed in Table 1.

The welding test mock-up configuration, fixture design, and weld bead locations were determined from preliminary testing with a travel speed of $34 \mathrm{~cm} / \mathrm{min}$, as follows:

1) Test materials of steels $L-C$ and $\mathrm{M}-\mathrm{C}$ were cut into the test coupons with dimensions of $300 \mathrm{~mm}$ in length $\times 50 \mathrm{~mm}$ in width. The thicknesses of the three test coupons were 20,40, and $80 \mathrm{~mm}$. Grooves of $6 \mathrm{~mm}$ in width $\times 12 \mathrm{~mm}$ in depth for steel L-C, and 3 $\mathrm{mm}$ in width $\times 12 \mathrm{~mm}$ in depth for steel $\mathrm{M}-\mathrm{C}$, were milled on one side of the test coupons. The other three sides of the test coupons were machined to $10 \mathrm{~mm}$ in thickness and $15 \mathrm{~mm}$ in width, as shown in Fig. $1 \mathrm{~A}$.

2) The welding test mock-ups were assembled from steel L-C and M-C test coupons, and butt-joint welded using the low- $C$ welding wire. The test coupons were thoroughly cleaned with acetone prior to welding, then restrained between backing restraining plates in the fixture. All bolts were

\section{A}
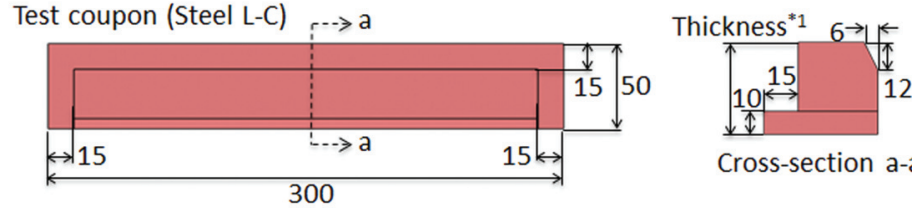

Cross-section a-a

Test coupon (Steel M-C) $r \rightarrow b$
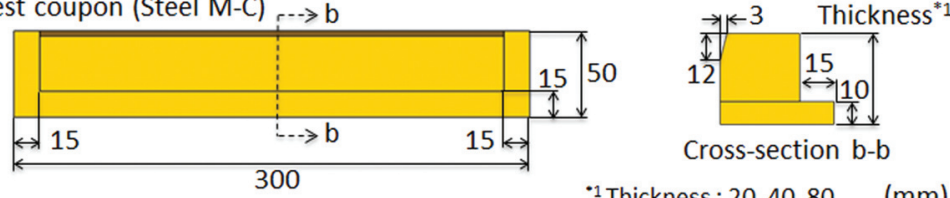

Cross-section $b-b$

${ }^{-1}$ Thickness : 20, 40, $80 \quad(\mathrm{~mm})$

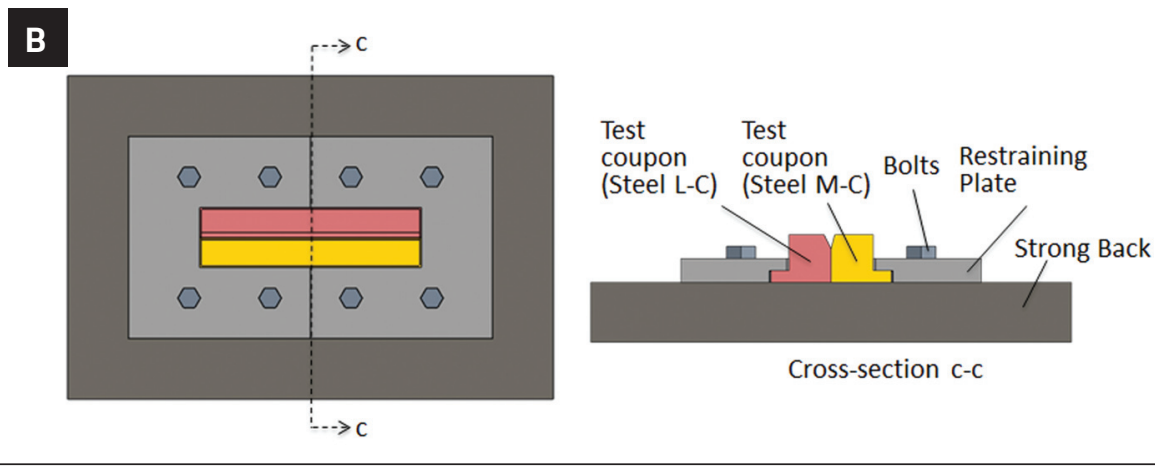

C

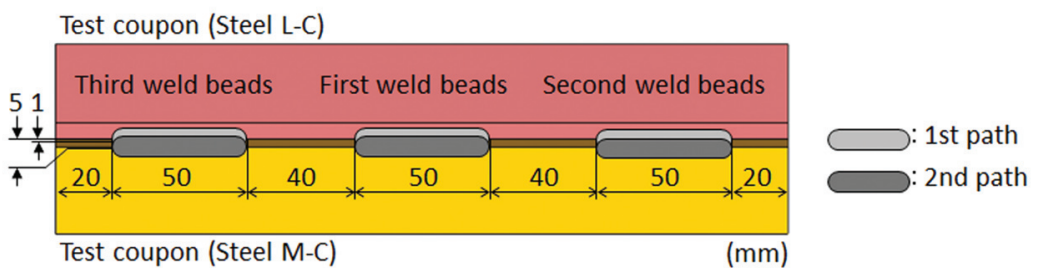

Fig. 1 - Schematic illustrations of the mock-ups for weld solidification cracking sus ceptibility testing: A - The configurations of test coupons for assembling the mock-up; B - assembled welding test mock-up (test coupons were restrained by bolts and restraining plates on a strong back); $C$ - welding sequence for $7^{\text {st }}$ and $2^{\text {nd }}$ pass weld beads on the groove of test coupons $L-C$ and $M-C$, and their bead length and location.

torqued to a fixed value to ensure consistent restraint conditions, as shown in Fig. 1B.

3) The weld beads were built up by two passes in the groove of the buttwelded joints to study solidification cracking susceptibility of the $1^{\text {st }}$ and $2^{\text {nd }}$ pass weld beads. The welding bead location was $1 \mathrm{~mm}$ from the center toward steel $\mathrm{M}-\mathrm{C}$ for the $1^{\text {st }}$ pass and 5 $\mathrm{mm}$ from the center toward steel $\mathrm{M}-\mathrm{C}$ for the $2^{\text {nd }}$ pass.

In this study, three mock-ups and weld bead locations for the $1^{\text {st }}$ and $2^{\text {nd }}$

Table 1-Chemical Compositions of the Test Materials (wt-\%)

\begin{tabular}{ccccccc} 
& $\mathrm{C}$ & $\mathrm{Si}$ & $\mathrm{Mn}$ & $\mathrm{P}$ & $\mathrm{S}$ & $\mathrm{Ti}+\mathrm{Zr}$ \\
\hline Steel L-C & 0.12 & 0.14 & 1.20 & 0.019 & 0.002 & - \\
Steel M-C & 0.34 & 0.24 & 0.82 & 0.013 & 0.003 & - \\
Filler Metal & 0.06 & 0.61 & 1.16 & 0.012 & 0.006 & 0.10 \\
\hline
\end{tabular}



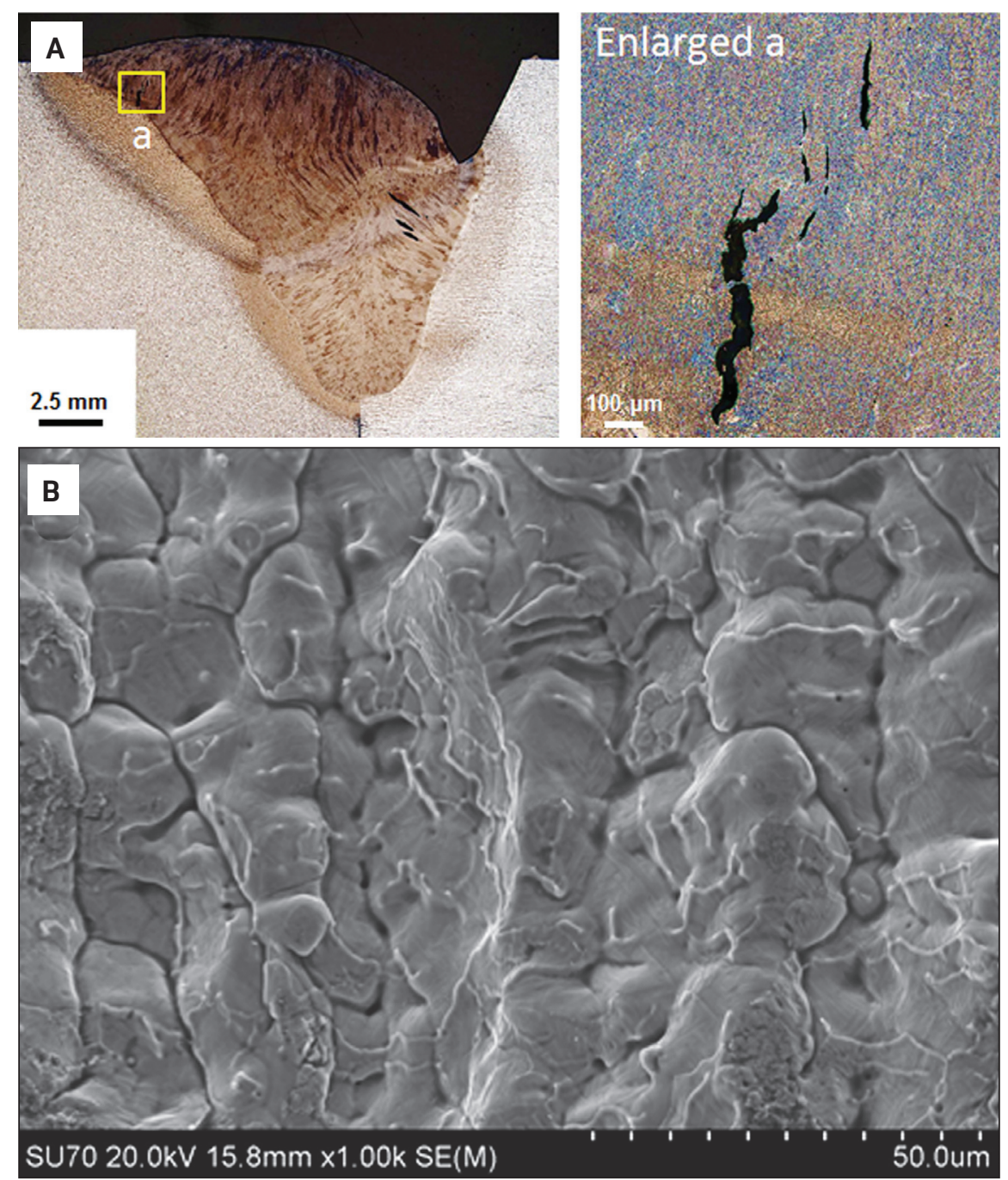

Fig. 2 - Typical solidification cracks in the $1^{\text {st }}$ and $2^{\text {nd }}$ pass weld beads: A - Optical microscopy of the cross section of the $1^{\text {st }}$ and $2^{\text {nd }}$ pass weld beads; B - SEM image of the solidification crack surface in the $1^{\text {st }}$ pass weld bead; C - IPF EBSD map near the solidification crack tip in the $2^{\text {nd }}$ pass weld bead. passes were used to study the effect of travel speed on solidification cracking susceptibility.
Six travel speeds were then used to evaluate their influence on solidification cracking susceptibility (Table 2).
Table 2 - Welding Parameters for the $1^{\text {st }}$ and $2^{\text {nd }}$ Pass Weld Beads between Test Coupons L-C and M-C

Current (A) Voltage (V) Travel Speed (cm/min) Heat Input (kJ/mm)

\begin{tabular}{|c|c|c|c|c|}
\hline Case 1 & & & 20 & 25.5 \\
\hline Case 2 & & & 27 & 18.9 \\
\hline Case 3 & & & 34 & 15.0 \\
\hline Case 4 & 300 & 28.3 & 49 & 10.4 \\
\hline Case 5 & & & 64 & 8.0 \\
\hline Case 6 & & & 80 & 6.4 \\
\hline
\end{tabular}

$6.5 \mathrm{~m} / \mathrm{min}$ wire feed speed.

$100^{\circ} \mathrm{C}$ interpass temperature for the $2^{\text {nd }}$ pass weld bead. $\mathrm{Ar}-20 \% \mathrm{CO}_{2}$ shielding gas.

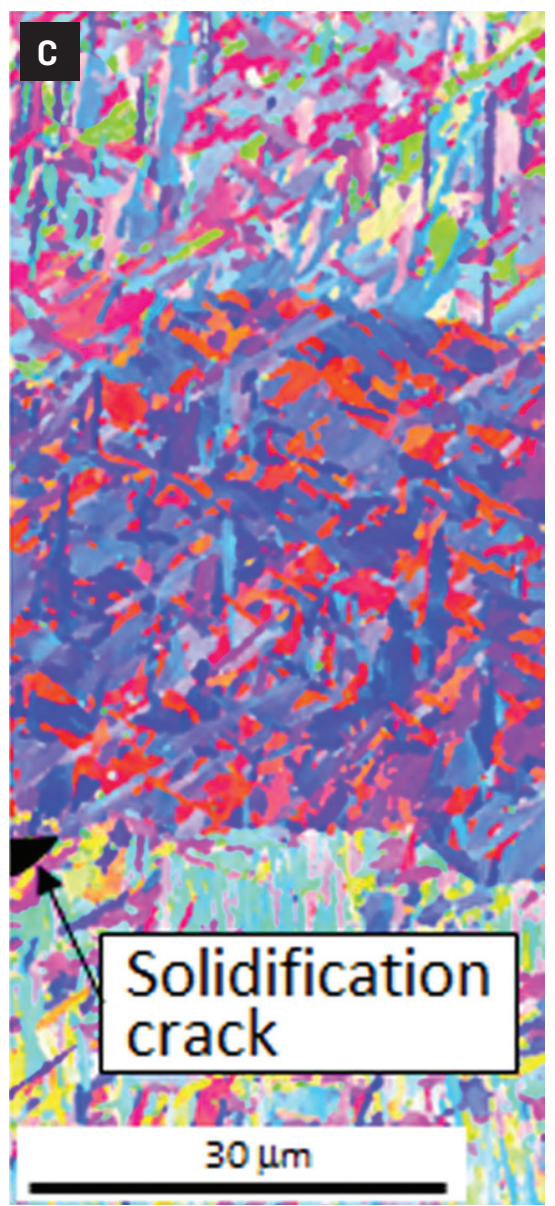

The travel speed was chosen in the range of 20 to $80 \mathrm{~cm} / \mathrm{mm}$ compared to $34 \mathrm{~cm} / \mathrm{min}$ used in the preliminary testing.

Three kinds of two-pass weld beads were built up at different locations by different travel speeds in the grooves of the welding test mock-ups, as shown in Fig. 1C. These build-up beads were 50 $\mathrm{mm}$ long with a spacing of $40 \mathrm{~mm}$. The welding order of these build-up beads was changed as follows. The first weld beads were built up in the center part of the mock-up. Then, the second weld beads were applied to the right side of the test mock-up, and the third weld beads were applied on the left side of the test mock-up. The interpass temperature for the $2^{\text {nd }}$ pass weld beads was controlled to about $100^{\circ} \mathrm{C}$ and monitored by a noncontact infrared radiation thermometer. The interpass temperature was measured from the industrial welded structure, where solidification cracks were observed in the $1^{\text {st }}$ and $2^{\text {nd }}$ pass weld beads. In addition, this temperature is used in practical auto welding machines without observing cold cracking or other weld defects. The 
shielding gas was Ar-20\% $\mathrm{CO}_{2}$ using a metal active gas semiautomatic welding machine. In this way, by using the same type of welding test mock-ups, the effect of six travel speeds on solidification cracking susceptibility was evaluated.

\section{Observation of Solidification Cracking and Analysis of Chemical Composition of the Weld Metal}

The welding test mock-ups, including the three buildup weld beads, were cut into three pieces containing each buildup weld bead. Each of these pieces was then cut into two specimens at the center of the length of each weld bead. One side of the test specimens of each of the buildup weld beads was polished by emery paper and diamond paste, and then etched by $2-3 \%$ Nital solution for metallography. Solidification cracks were examined on cross sections of polished and etched test specimens by optical microscopy, scanning electron microscopy (SEM), EDS, and electron backscatter diffraction (EBSD) using a Hitachi SU-70 electron microscope.

The opposite sides of each test specimen of the buildup beads were ground by a $\mathrm{SiC}$ grinder. For these specimens, glow discharge optical emission spectrometry (GDOES) using a GD-Profiler2 provided quantitative analysis of the chemical composition of the weld metal. It is believed that the amount of low- $C$ welding wire and the dilution ratios of steels $\mathrm{L}-\mathrm{C}$ and $\mathrm{M}$ $C$ in the weld pool change due to the travel speed. Therefore, the location of the GDOES analysis was at the center of the weld metal to measure the changes of the chemical composition by the travel speed. Before the analyses, quantitative GDOES calibration curves for the emission intensities of $\mathrm{C}, \mathrm{Si}, \mathrm{Mn}, \mathrm{P}$, and $\mathrm{S}$ were obtained using five different commercial carbon steels.

\section{Analysis of $\mathbf{S}$ and $\mathrm{P}$ Compounds on Solidification Cracks}

To analyze any $\mathrm{S}$ and/or $\mathrm{P}$ compounds at the solidification crack tips by EDS, test specimens with solidification cracks in the analyzed location

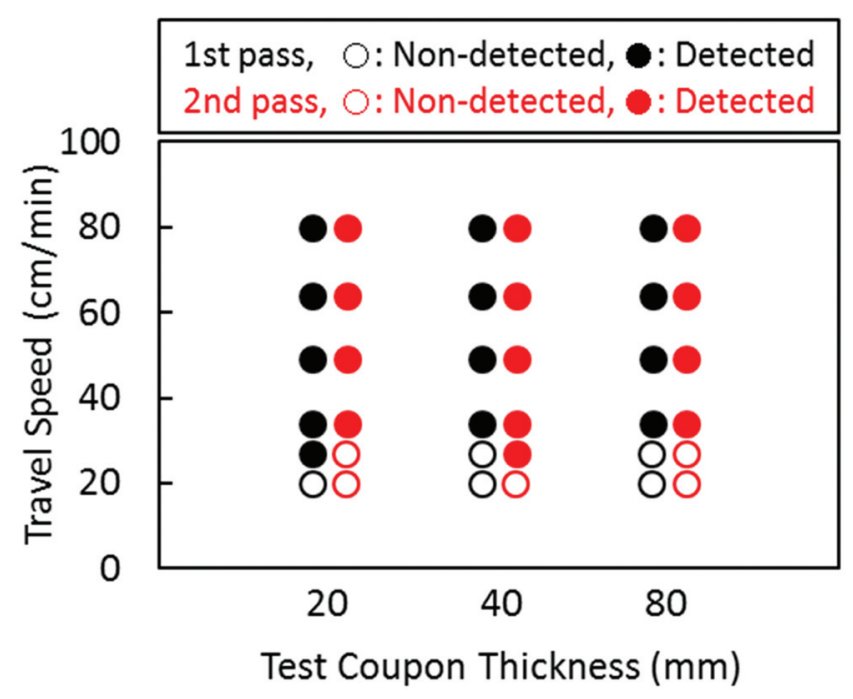

Fig. 3-Combined effect of test coupon thickness and travel speed on detected or nondetected solidification cracking in the $1^{\text {st }}$ and $2^{\text {nd }}$ pass weld beads.

were cut from the larger solidification crack containing pieces. These specimens were ground and polished by emery paper and diamond paste.

In addition, the $S$ and/or $P$ compounds on the fracture surfaces of solidification cracks were analyzed by AES using a ULVAC-PHI SAM680 Auger spectrometer. The 2-mmdiameter test specimens for AES were machined containing solidification cracks in the analyzed location of the weld metal. The AES test specimens were fractured by the tensile testing machine within the AES spectrometer at a slow strain rate of $0.001 \mathrm{~mm} / \mathrm{min}$ in an ultrahigh vacuum. The in-situ fracture surface of a solidification crack was then studied to identify the $\mathrm{S}$ and $\mathrm{P}$ compounds.

\section{Results}

\section{Solidification Cracking Susceptibility Testing Using Weld Mock-Ups}

Figure 2A shows solidification cracks in the $1^{\text {st }}$ and $2^{\text {nd }}$ pass weld beads prepared at the $34 \mathrm{~cm} / \mathrm{min}$ travel speed on 20-mm-thick test coupons. Few solidification cracks were observed in the $1^{\text {st }}$ and $2^{\text {nd }}$ pass weld beads. Figure 2B shows a SEM image of a solidification crack surface. The dendrite structure was observed on the fracture surface. In addition, Fig.
$2 \mathrm{C}$ shows an inverse pole figure (IPF) map of the solidification crack tip. Based on fractography and IPF mapping, the solidification cracks were located along the dendrite boundaries.

Figure 3 shows the effect of the combinations of conditions for test coupon thickness and travel speed for the detection of solidification cracking in the $1^{\text {st }}$ and $2^{\text {nd }}$ pass weld beads. In the $1^{\text {st }}$ pass weld bead, solidification cracking was detected at the travel speed over 34 $\mathrm{cm} / \mathrm{min}$ for all test coupon thicknesses. The same result was observed for the $2^{\text {nd }}$ pass weld bead. By contrast, solidification cracking was not detected in both the $1^{\text {st }}$ and $2^{\text {nd }}$ pass weld beads at a travel speed of $20 \mathrm{~cm} / \mathrm{min}$.

\section{C, S, and P Contents in the Weld Metal vs. Travel Speed}

Figure $4 \mathrm{~A}, \mathrm{~B}$, and $\mathrm{C}$ show the $\mathrm{C}, \mathrm{S}$, and $P$ contents of the weld metal of the $1^{\text {st }}$ and $2^{\text {nd }}$ pass weld beads vs. travel speed. The $C$ content of the weld metal of the $1^{\text {st }}$ pass weld bead gradually increased from 0.18 to $0.22 \mathrm{wt}-\%$ with increasing travel speed. However, the $\mathrm{S}$ and $\mathrm{P}$ contents of the weld metal were not different at the different travel speeds.

In addition, the $S$ content of the weld metal was low at 0.003 to 0.005 wt- $\%$, and the P content was 0.016 to 0.017 wt- $\%$. The $C$ content of the weld metal of the $2^{\text {nd }}$ pass weld bead gradually increased from 0.14 to $0.24 \mathrm{wt}-\%$ 

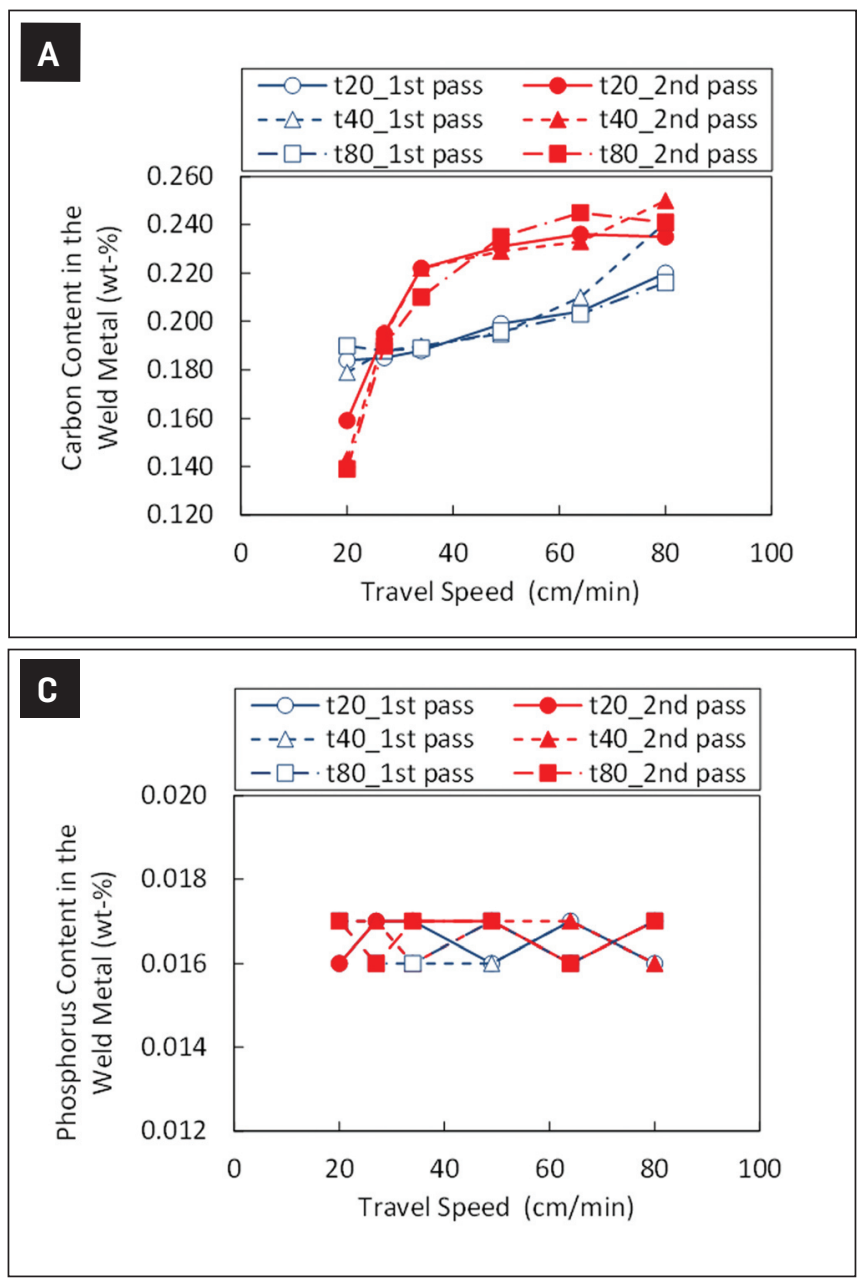

$C$ with increasing travel speed, as also observed in the $1^{\text {st }}$ pass weld bead. The $S$ and $P$ contents of the weld metal were not different at the different travel speeds. The $S$ content of the $2^{\text {nd }}$ pass weld bead was low at 0.004 to 0.006 wt-\%, and the $\mathrm{P}$ content was 0.016 to 0.017 wt-\%.

\section{Total Length of Solidification Cracks vs. C Content of the Weld Metal}

The total length of the solidification cracks was determined to compare the solidification cracking susceptibility and the $C$ content of the weld metal. The total length of the solidification cracks in the $1^{\text {st }}$ and $2^{\text {nd }}$ pass weld beads depended on the $C$ content of the weld metal, as shown in Fig. 5. In addition, it can be seen that the total length of the solidification cracks in the $1^{\text {st }}$ and $2^{\text {nd }}$ pass weld beads increased above approximately 0.18 wt-\% C content in the weld metal.

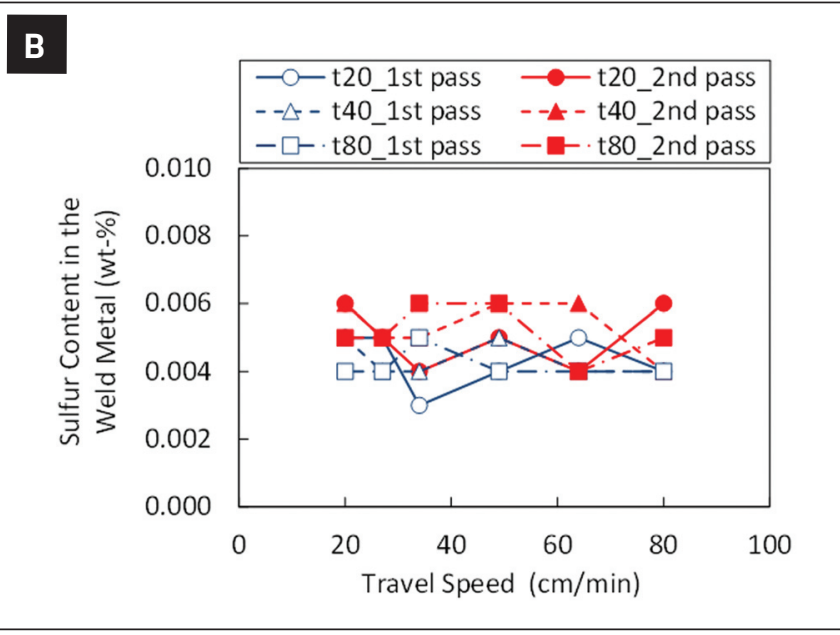

Fig. 4-Chemical composition of the weld metal of the $7^{\text {st }}$ and $2^{\text {nd }}$ pass weld beads vs. travel speed: A - Carbon content; $B-$ sulfur content; $C$ - phosphorus content.

\section{$S$ and $P$ Compounds Formed on Solidification Cracks}

EDS maps of iron (Fe), manganese (Mn), S, and P were obtained to identify the segregation of these elements near the solidification crack tips. Figure 6 shows SEM images and EDS maps of these elements. Particles of MnS were detected on the fracture surfaces of the solidification cracks. By contrast, phosphorous was not detected on the solidification cracks.

The AES maps of Fe, Mn, S, and P as well as spectrum analyses were used to identify the segregation of elements at the fracture surface of the solidification cracks. Figure 7A shows an SEM image and AES maps of these elements on the fracture surface of the solidification cracks after tensile testing at a slow strain rate in an ultrahigh vacuum. In the AES maps of Fe, Mn, S, and $\mathrm{P}$ on the solidification crack fracture surfaces, higher, lower, and very low concentrations of $\mathrm{S}$ were detected on points (a), (b), and (c), respectively.

There is a correlation between the high $S$ and Mn locations, which is evidence for the MnS particles being formed on the fracture surfaces of the solidification cracks. In part of the fracture surface, which is surrounded by a yellow rectangle in Fig. 7A, only iron was detected and $\mathrm{Mn}, \mathrm{S}$, and $\mathrm{P}$ were not present at that location. It was concluded that this location was not a solidification crack but a mechanically fractured region during the tensile testing. By contrast, phosphorous was not detected by AES on the fracture surface of the solidification cracks.

Figure 7B shows the result of AES spectrum analyses at the points (a) and (b). Peaks of $S$, chlorine $(\mathrm{Cl}), \mathrm{C}$, nitrogen (N), Mn, and Fe were observed, but the peak for carbide was not observed at points (a) and (b). Therefore, the peaks of $\mathrm{C}, \mathrm{Cl}$, and $\mathrm{N}$ may have been partly due to contamination. The atomic concentrations of $\mathrm{Mn}$ and $\mathrm{S}$ were estimated with the peaks of Mn and $S$ from the AES spectrum analyses to determine the $S$ compound at points (a) and (b) based on the ISO18118:2015 standard. According to ISO18118:2015, the atomic concentration of the element on the surface is given by

$$
X_{i}=\frac{\left(\frac{I_{i}}{S_{i}^{R S F}}\right)}{\sum_{j=1}^{n}\left(\frac{I_{j}}{S_{j}^{R S F}}\right)}
$$

where $X_{i}$ is the atomic concentration of the element; i $I_{i}$; and $I_{j}$ are measured peak intensities of elements $i$ and $j$; and $S_{i}^{R S F}$ and $S_{j}^{R S F}$ are the relative sensi- 
tivity factors for elements $i$ and $j$. The relative sensitivity factor $S_{i}^{R S F}$ is obtained with the following equation:

$$
S_{i}^{R S F}=\frac{I_{i}^{r e f}}{I_{k e y}}
$$

where $I_{i}^{r e f}$ is the peak intensity of the pure element $i$, and $I_{k e y}$ is the measured peak intensity of the key material. The relative sensitivity factors of $\mathrm{Mn}$ and $\mathrm{S}$ were 0.122 and 0.652 , respectively, which are taken from the database of PHI MultiPak ${ }^{\mathrm{TM}}$ version 9. Pure silver was used as $I_{k e y}$ to estimate the relative sensitivity factor of $\mathrm{Mn}$ and $\mathrm{S}$ in the database.

Table 3 shows the results of the estimated peak intensities of $\mathrm{Mn}$ and $\mathrm{S}$ from the AES spectrum analyses and the atomic concentrations of $\mathrm{Mn}$ and S at points (a) and (b) in Fig. 7B. The Mn and $S$ concentrations were 54.3 and 45.7 at.- $\%$, respectively, at point (a). As the Mn concentration was higher than the $S$ concentration, the $S$ compound was considered to be MnS. By contrast, the $\mathrm{Mn}$ and $\mathrm{S}$ concentrations were 45.5 and 54.5 at.-\%, respectively, at point (b). Because the $\mathrm{S}$ atomic concentration was higher than the Mn concentration, the $S$ compound was considered to also contain FeS, i.e., the compound can be represented by $(\mathrm{Fe}, \mathrm{Mn}) \mathrm{S}$.

\section{Discussion}

\section{Effect of $S$ and $M n / S$ Ratio on Solidification Cracking Susceptibility of Carbon Steel Weld Metal}

Ohshita et al. and Shankar et al. reported that the solidification cracking susceptibility in the case of 0.05 to 0.1 wt-\% $C$ steels can be attributed to the additional shrinkage strains associated with $\delta$ ferrite to austenite transformation taking place within the brittleness temperature range during solidification (Refs. 6, 9). By contrast, Bailey et al. reported that the solidification cracking was promoted by $C, S$, and P. In addition, reducing the $C$ content below 0.08 $\mathrm{wt}-\%$ gave no further improvement in cracking resistance, although carbon promoted solidification cracking (Ref. 10). In the case of $0.08 w t-\% C$ or less, $\delta$ ferrite + austenite formed from the $\delta$ -

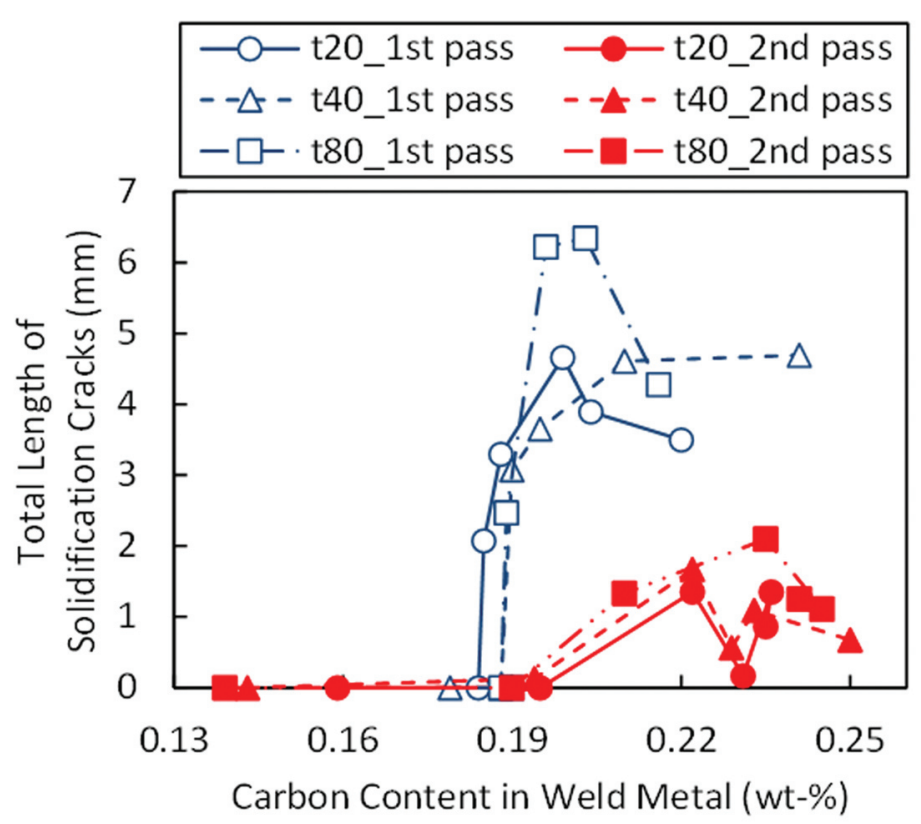

Fig. 5 - Correlation between the total crack length of solidification cracks in the $7^{\text {st }}$ and $2^{\text {nd }}$ pass beads vs. $C$ content of the weld metal.

Table 3 - Estimated Mn and S Concentration (at.-\%) on the Fracture Surfaces of Solidification Cracks, the Relative Sensitivity Factors, and the Peak Intensities of $\mathrm{Mn}$ and $\mathrm{S}$ for AES Spectrum Analysis

\begin{tabular}{ccccc} 
& \multicolumn{2}{c}{ Peak Intensity } & \multicolumn{2}{c}{ Atomic Concentration (at.-\%) ${ }^{(\mathrm{b})}$} \\
& $\mathrm{I}_{\mathrm{Mn}}$ & $\mathrm{I}_{\mathrm{s}}$ & $\mathrm{X}_{\mathrm{Mn}}$ & $\mathrm{X}_{\mathrm{s}}$ \\
\hline Point (a) & 23122 & 104126 & 54.3 & 45.7 \\
Point (b) & 6290 & 40316 & 45.5 & 54.5 \\
\hline
\end{tabular}

(a) Measured peak intensity of $\mathrm{Mn}$ and $\mathrm{S}$ of AES spectrum analysis.

(b) $\mathrm{X}_{\mathrm{Mn} \text { or } \mathrm{S}}$ are the atomic concentration of $\mathrm{Mn}$ and $\mathrm{S}$ based on the IS018118:2015 standard.

$X_{i}=\frac{\left(\frac{I_{i}}{S_{i}^{R S F}}\right)}{\sum_{j=1}^{n}\left(\frac{I_{j}}{S_{j}^{R S F}}\right)}, i, j=$ Mn or $S$

$S_{M n}^{R S F}$ is the relative sensitivity factor $\mathrm{Mn} 0.122$

$S_{S}^{R S F}$ is the relative sensitivity factor $\mathrm{S} 0.652$.

ferrite phase during the peritectic reaction (Ref. 11). In the case of 0.08 to 0.16 wt-\% C, $\delta$ ferrite + austenite formed from liquid $+\delta$ ferrite. The difference between these phase transformations is the presence of the liquid phase. It is assumed that the solidification cracking susceptibility is attributed to the decreasing solidification temperature due to segregation of impurity elements to the liquid phase when more than 0.08 wt-\% C. The solidification 


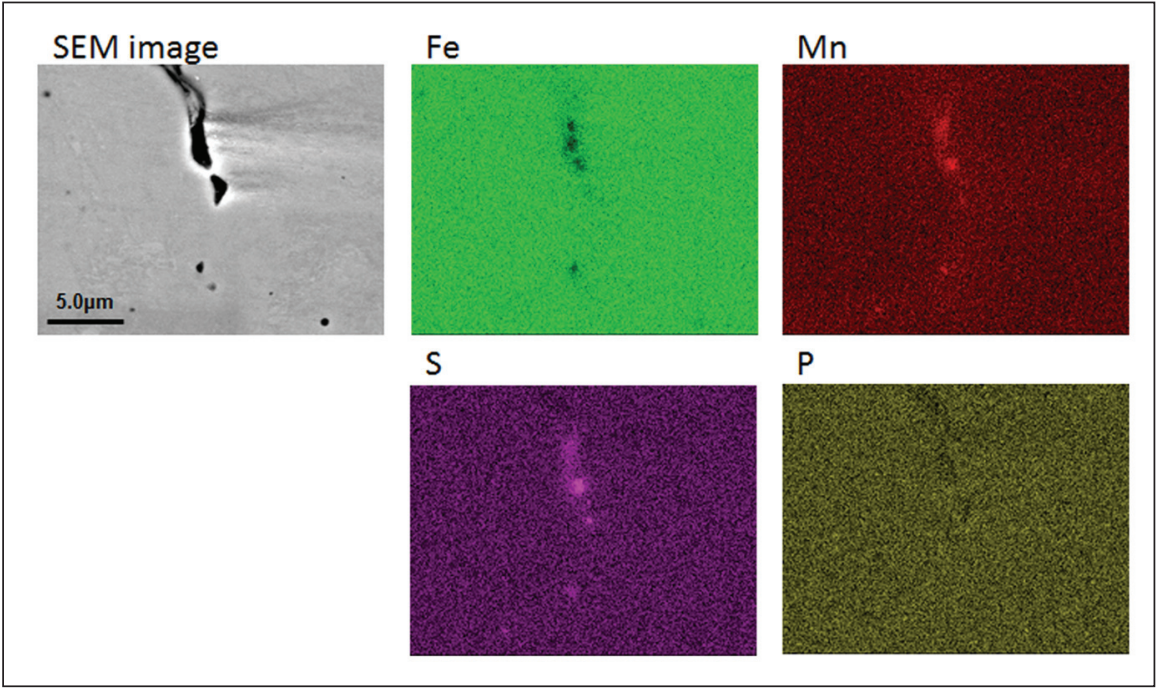

Fig. 6 - SEM image and EDS maps of Fe, Mn, S, and P of a solidification crack on the cross section of the $1^{\text {st }}$ pass weld bead.

cracking susceptibility is associated with the shrinkage strains in the weld metal due to the austenite forming from the $\delta$ ferrite in the case of $0.08 \mathrm{wt}-\%$ C or less. In this study, $\mathrm{C}$ contents of the weld metals were 0.14 to 0.24 wt- $\%$ and S compounds were detected on the fracture surfaces of the solidification cracks, as shown in Fig. 7. Therefore, the effect of $S$ in the weld metal on the solidification cracking susceptibility was studied.
Lancaster reported that an adequate amount of Mn tends to inhibit the deleterious effect of $S$ and that a $\mathrm{Mn} / \mathrm{S}$ (wt-\%) ratio in carbon steel weld metal of $>50$ reduces significantly solidification cracking susceptibility (Ref. 12).

Senda et al. found that the solidification cracking occurs because of the lower solidification temperature of the $\mathrm{Fe}-(\mathrm{Mn}, \mathrm{Fe}) \mathrm{S}-(\mathrm{Fe}, \mathrm{Mn}) \mathrm{S}$ ternary eutec- tic in the solid-liquid region. By contrast, the solidification temperature of $\mathrm{MnS}$ particles is approximately $1620^{\circ} \mathrm{C}$, which is higher than that of the ternary eutectic. Therefore, increasing amounts of $\mathrm{Mn}$ and $\mathrm{S}$ in the solid-liquid region during solidification were studied to determine the equilibrium distribution coefficients of these elements. The Mn content to the fifth power vs. S $\left(\mathrm{Mn}^{5} / \mathrm{S}\right)$ was observed, independent of the solid phase present, to be the same composition ratio in the solid-liquid region. The $\mathrm{Mn}$ and S contents were examined to reduce solidification cracking susceptibility with $\mathrm{Mn}^{5} / \mathrm{S}$ as the preferred measure of solidification cracking susceptibility. In the case of carbon steel, which contains approximately $1 \mathrm{wt}-\%$ $\mathrm{Mn}, \mathrm{Mn}^{5} / \mathrm{S}$ (wt-\%) ratios <14-26 increased solidification cracking susceptibility due to the low solidification temperature of the ternary eutectic. By contrast, $\mathrm{Mn}^{5} / \mathrm{S}$ (wt-\%) ratios of 310-560 reduced solidification cracking susceptibility due to MnS particle formation (Ref. 13).

Both $\mathrm{Mn} / \mathrm{S}$ and $\mathrm{Mn}^{5} / \mathrm{S}$ ratios were estimated from the $\mathrm{Mn}$ and $\mathrm{S}$ contents (wt-\%) of the weld metal as analyzed by GDOES. Table 4 shows the results for the $\mathrm{Mn} / \mathrm{S}$ and $\mathrm{Mn}^{5} / \mathrm{S}$ ratios of the

Table 4 - Estimated Mn/S and $\mathrm{Mn}^{5} / \mathrm{S}$ Ratios of the Weld Metal as Potential Parameters to Determine the Solidification Cracking Susceptibility

\begin{tabular}{|c|c|c|c|c|}
\hline Weld Bead Pass & $\begin{array}{l}\text { Travel Speed } \\
\text { (cm/min) }\end{array}$ & Mn/S Ratios ${ }^{(a)}$ & $\mathrm{Mn}^{5} / \mathrm{S}$ Ratios ${ }^{(\mathrm{b})}$ & Solidification Cracking(c) \\
\hline \multirow{6}{*}{$1^{\text {st }}$ pass } & 20 & 194 & 173 & Nondetected \\
\hline & 27 & 216 & 294 & Detected \\
\hline & 34 & 353 & 443 & Detected \\
\hline & 49 & 247 & 235 & Detected \\
\hline & 64 & 198 & 188 & Detected \\
\hline & 80 & 243 & 217 & Detected \\
\hline \multirow{6}{*}{$2^{\text {nd }}$ pass } & 20 & 164 & 154 & Nondetected \\
\hline & 27 & 214 & 283 & Nondetected \\
\hline & 34 & 267 & 347 & Detected \\
\hline & 49 & 215 & 288 & Detected \\
\hline & 64 & 253 & 267 & Detected \\
\hline & 80 & 177 & 226 & Detected \\
\hline
\end{tabular}

(a) Mn vs. S ratio.

$\mathrm{Mn} / \mathrm{S}$ ratios above 50 reduce solidification cracking susceptibility (Ref. 9).

(b) Mn to the fifth power vs. $S$ ratio.

$\mathrm{Mn}^{5} / \mathrm{S}$ ratios of $310-560$ reduce solidification cracking susceptibility (Ref. 10).

(c) Detected or nondetected solidification cracking on the cross section of weld metal. 
weld metals for the test coupon thickness of $20 \mathrm{~mm}$. The same tendency was confirmed for the test coupons of 40 and $80 \mathrm{~mm}$ in thickness. The $\mathrm{Mn} / \mathrm{S}$ ratio was over 50 in the weld metals for all the travel speeds studied.

However, solidification cracking was detected in the $1^{\text {st }}$ pass weld bead only at travel speeds $>27 \mathrm{~cm} / \mathrm{min}$ and in the $2^{\text {nd }}$ pass weld bead at travel speeds $>34 \mathrm{~cm} / \mathrm{min}$. In addition, the solidification cracking susceptibility was not precisely determined by the $\mathrm{Mn}^{5} / \mathrm{S}$ ratio. For example, solidification cracking was not detected in the $1^{\text {st }}$ pass weld bead at the travel speed $20 \mathrm{~cm} / \mathrm{min}$, even though the $\mathrm{Mn}^{5} / \mathrm{S}$ ratio was not in the range $310-560$. It is believed that the $\mathrm{Mn} / \mathrm{S}$ and $\mathrm{Mn}^{5} / \mathrm{S}$ ratios do not take into account the different solubility of $S$ in $\delta$ ferrite and in austenite. The amount of $\delta$ ferrite and austenite phases depend on the $C$ content of the weld metal during the peritectic reaction. Consequently, the effect of $C$ content on the solidification cracking susceptibility of the weld metal during the peritectic reaction was evaluated as follows.

\section{Effect of Carbon Content on Solidification Cracking Susceptibility during the Peritectic Reaction}

The relationship between the total length of the solidification cracks formed in the test coupon of $20 \mathrm{~mm}$ thickness, and the $C$ content of the weld metal, was evaluated using the peritectic reaction for the $\mathrm{Fe}-\mathrm{C}$ binary equilibrium phase diagram, as shown in Fig. 8 (Ref. 11). The equilibrium phase diagram is not directly applicable in the case of rapid solidification of weld metal. Therefore, it was assumed that the ratio of phases formed during the transformation does not change even though the peritectic reaction occurs by rapid solidification. The occurrence of a peritectic reaction in the case of rapid solidification is well known in the literature (Refs. 14-16).

The amounts of $\delta$ ferrite or austenite phases in the solid-liquid region during the peritectic reaction changes as a function of the $C$ content in the carbon steel weld metal:

1) Region I (up to $0.08 \mathrm{wt}-\% \mathrm{C}$ ): $\delta$ ferrite phase forms from (liquid $+\delta$
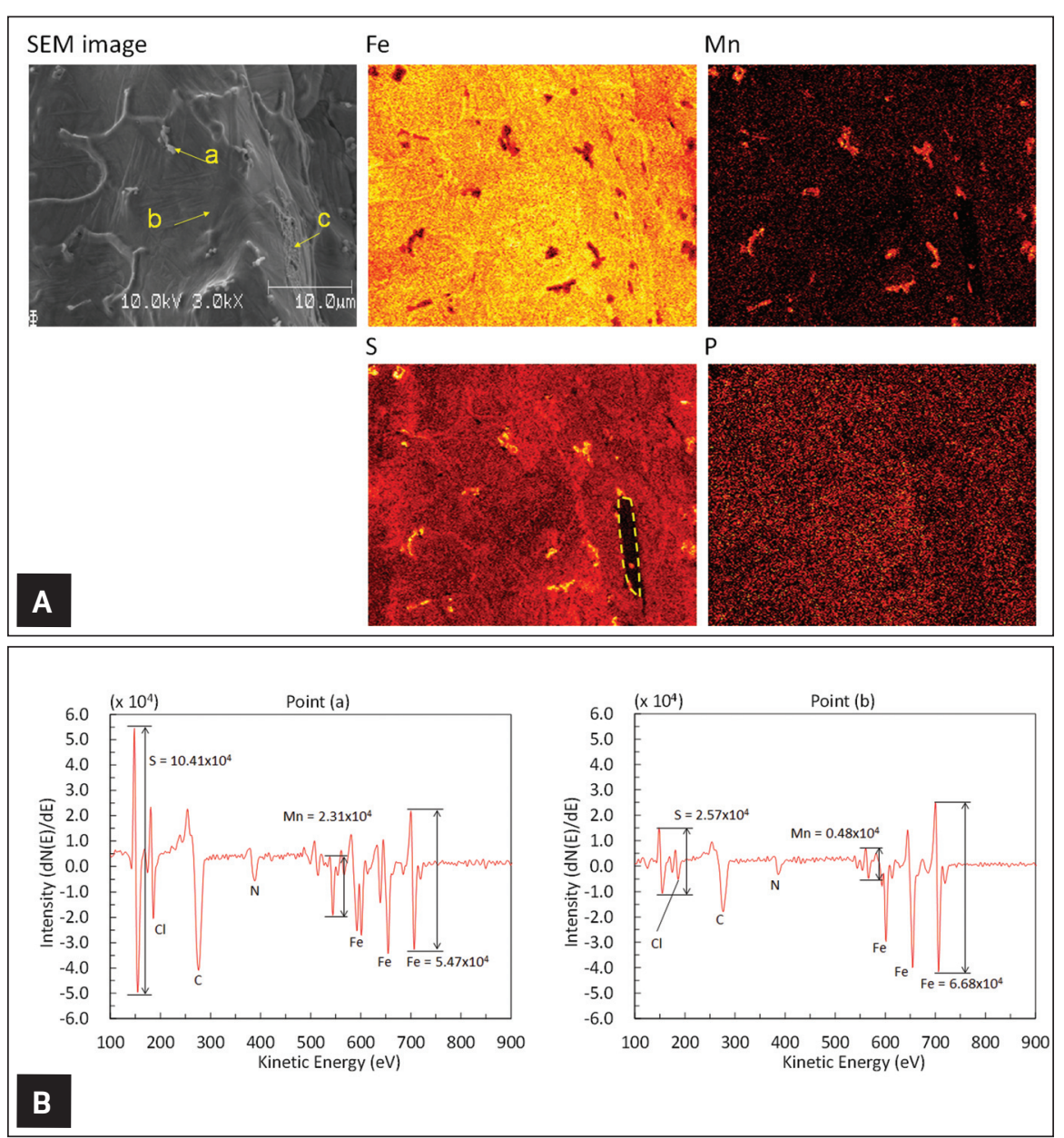

Fig. 7 - SEM image, AES maps, and spectra on the fracture surface of a solidification crack of a tensile test specimen tested at a slow strain rate to fracture in an ultrahigh vacuum: $A-S E M$ image and AES maps of $F e, M n, S$, and $P ; B-A E S$ spectra at points (a) and (b) of the SEM image.

ferrite), and then ( $\delta$ ferrite + austenite) forms from the $\delta$-ferrite phase.

2) Region II (0.08 to 0.16 wt-\% C): ( $\delta$ ferrite + austenite) forms from (liquid $+\delta$ ferrite) .

3) Region III (0.16 to $0.51 \mathrm{wt}-\% \mathrm{C})$ : (austenite + liquid) forms from ( $\delta$ ferrite + liquid).

The $\delta$ ferrite forms as a solid phase during the peritectic reaction in Regions I and II. By contrast, in Region III, austenite phase forms in the solidification reaction. The transformation ratio of the austenite phase increases with increasing $C$ content in the solidliquid two-phase region of Region III. The solubility of $S$ in the $\delta$-ferrite phase and austenite phase is 0.14 and 0.05 wt-\%, respectively, at the temperature of $1365^{\circ} \mathrm{C}$. The solubility of $\mathrm{S}$ in the austenite phase decreases with decreasing temperature from $1365^{\circ}$ to $912^{\circ} \mathrm{C}$ (Ref. 11). In addition, it is considered that the austenite phase forms at the lower temperature due to undercooling in the case of rapid solidification.

Therefore, the austenite phase with low solubility of S forms in Region III. For these reasons, the $S$ content in the remaining liquid phase increases with increasing transformation ratio of the austenite phase in the solid-liquid region of Region III shown in Fig. 8. Figure 7 shows that $S$ compounds identified as probably FeS and (Fe, Mn)S were present on most areas of the fracture surfaces of solidification cracks.

Matsuura et al. reported that FeS and $(\mathrm{Fe}, \mathrm{Mn}) \mathrm{S}$ on grain and dendrite boundaries form as the eutectic sulfide of Fe-MnS-FeS ternary eutectic (Ref. 17). The solidification temperature of the eutectic is about $1000^{\circ} \mathrm{C}$, which is much lower than the solidification temperature of the carbon steel weld metal (Ref. 18). 


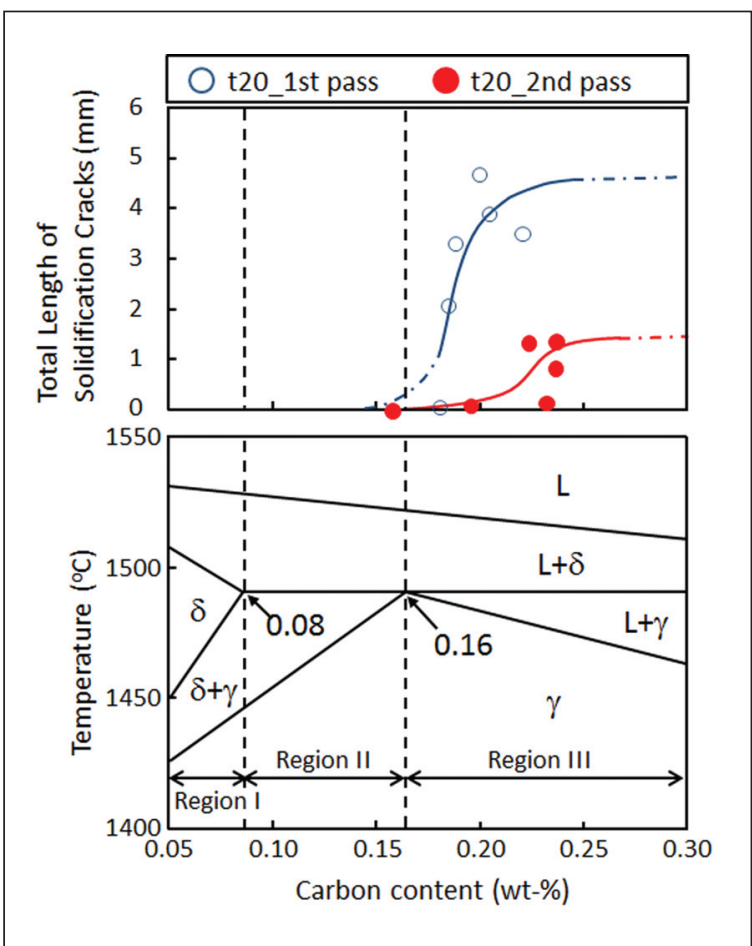

Fig. 8 - Relationship between the total length of detected solidification cracks on the cross section of weld metal and the $C$ content of the equilibrium binary Fe-C phase diagram.

In the case of Region III of Fig. 8, the $S$ content in the remaining liquid phase increases with increasing transformation ratio of the austenite phase in the solid-liquid region. Therefore, the solidification cracking susceptibility of the carbon steel weld metal increases with increasing $C$ content due to the decreasing solidification temperature of the Fe-MnS-FeS eutectic. By contrast, in the case of Regions I and II, the $S$ content in the remaining liquid phase decreases with increasing transformation ratio of the $\delta$-ferrite phase in the solid-liquid region. Thus, solidification cracking susceptibility of carbon steel weld metal decreases with decreasing $C$ content.

To verify the decreasing solidification cracking susceptibility of carbon steel weld metal with decreasing $C$ content, the same experiments were conducted using the steel L-C and the low- $C$ welding wire as shown in Table 1. A travel speed of $80 \mathrm{~cm} / \mathrm{min}$ was used (Table 2). The thicknesses of the test coupons were 20,40 , and $80 \mathrm{~mm}$. Figure 9 shows the optical macrographs of the weld cross sections of 0.23 and $0.11 \mathrm{wt}-\% \mathrm{C}$ in the $1^{\text {st }}$ pass, as well as 0.24 and 0.11 wt-\% $C$ in the $2^{\text {nd }}$
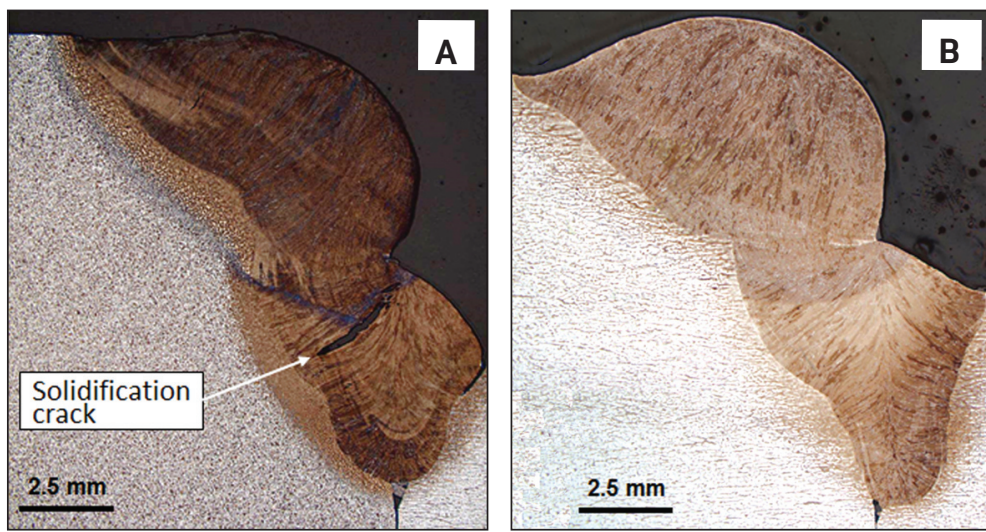

Fig. 9-Optical microscopy of the cross- section of $7^{\text {st }}$ and $2^{\text {nd }}$ pass weld beads: $A-0.22$ and $0.24 \mathrm{wt}-\% \mathrm{C}$ in the $1^{\text {st }}$ and $2^{\text {nd }}$ pass weld beads, respectively; $B-0.11$ wt-\% $C$ in the $1^{\text {st }}$ and $2^{\text {nd }}$ pass weld beads.

pass weld metal, respectively, at the $80 \mathrm{~cm} / \mathrm{min}$ travel speed on a $20-\mathrm{mm}$ thick test coupon. Solidification cracking was not detected at a low- $C$ content for both the $1^{\text {st }}$ and $2^{\text {nd }}$ pass weld beads for the studied plate thicknesses. The experimental results were in good agreement with the decreasing solidification cracking susceptibility at a low-C content of the weld metal.

\section{Effect of Travel Speed on Solidification Cracking Susceptibility of Carbon Steels with Different Carbon Contents}

As a result of weld testing using mock-ups (which consisted of the lowC steel L-C test coupon, and the medium- $C$ steel $M-C$ test coupon welded by the low- $C$ welding wire), the $C$ content of the weld metal increased with increasing travel speed, as shown in Fig. 4 . In addition, the $S$ content in the $1^{\text {st }}$ and $2^{\text {nd }}$ pass weld metals did not change even when the travel speed changed. These results are interpreted as follows:

1) The amount of low- $C$ welding wire per test coupon in the weld metal decreased with increasing travel speed. Therefore, the $C$ content of the weld metal increased with the increasing travel speed.

2) The $S$ contents of steels L-C and $\mathrm{M}-\mathrm{C}$, and the welding wire were low.
Thus, the $S$ and $P$ contents in the weld metal did not change with the travel speed.

The solidification cracking susceptibility increased with increasing $C$ content in Region III, as shown by the results in Fig. 8. Therefore, the solidification cracking susceptibility of the weld metal increased with increasing travel speed due to the increasing amount of the austenite phase formed in the solid-liquid region.

It was considered that the solidification cracking susceptibility of the weld metal for different $C$ content carbon steels was affected by the travel speed due to the change of $C$ content and the increasing amount of austenite phase formed in the weld metal, even though the $S$ content was low. By contrast, in the case of a very low travel speed, it was believed that the solidification cracking susceptibility became low due to the decreasing $C$ content of the weld metal and the increasing amount of $\delta$ ferrite formed in the solid-liquid region.

\section{Conclusions}

Carbon steels with low S and P contents can be susceptible to solidification cracking, when carbon steels with different $C$ contents are welded by a low- $C$ welding wire.

To clarify the mechanism of solidification cracking of the low $\mathrm{S}$ and $\mathrm{P}$ carbon steels with different $C$ contents, the effect of travel speed on solidification cracking susceptibility was studied together with the identification by EDS and AES of the $\mathrm{S}$ and/or $\mathrm{P}$ 
compounds formed on the fracture surfaces of the solidification cracks.

From these results, the following mechanisms are considered to operate:

In the case of the higher travel speed, the amount of low- $C$ welding wire in the weld pool relative to low/medium $C$ base steels decreases, and the $C$ content in the weld metal increases with increasing travel speed. Therefore, in the solid-liquid region, the amount of austenite phase increases and the $S$ content in the remaining liquid phase increases with the increasing travel speed. The solidification temperature decreases due to the formation of a Fe-MnS-FeS eutectic. Solidification cracking susceptibility then increases with increasing travel speed.

In the case of the lowest travel speed, the amount of the welding wire in the weld pool relative to the base steels increases and the $C$ content in the weld metal decreases. Therefore, in the solid-liquid region, the amount of the $\delta$-ferrite phase increases and the $S$ content in the remaining liquid phase decreases. Consequently, the solidification cracking susceptibility decreases.

\section{References}

1. Senda, T., Matsuda, F., Takano, G., Watanabe, K., Kobayashi, T., and Matsuzaka, T. 1972. Studies of solidification crack susceptibility for weld metals with TransVarestraint test (1). J. Jpn. Weld. Soc. 41:
709-723 (in Japanese).

2. Senda, T., Matsuda, F., Nakagawa, H., Watanabe, K., and Matsusaka, T. 1974. Sulphide and its effect on solidification cracking in weld metal of steel (Report 5). J. Jpn. Weld. Soc. 43: 57-65 (in Japanese). 3. Masumoto, I., and Ozaki, H. 1973. Effect of carbon content on the hot cracking in solidified steel. J. Jpn. Weld. Soc. 42: 674-684 (in Japanese).

4. Tamaki, K., Kawakami, H., and Suzuki, J. 2002. Effect of carbon content and peritectic reaction on the hot cracking of weld metal of high carbon steel. J. Jpn. Weld. Soc. 20: 266-275 (in Japanese).

5. Randall, M. D., Monroe, R. E., and Nichols, H. J. 1961. Study of the causes of cracking in submerged-arc welds in constructional alloy steels. Welding Journal 40(9): 385-s to 392-s.

6. Ohshita, S., Yurioka, N., Mori, N., and Kimura, T. 1983. Prevention of solidification cracking in very low carbon steel welds. Welding Journal 62(5): 129-s to 136-s.

7. Khallaf, M. E., Ibrahim, M. A., EI-Mahallawy, N. A., and Taha, M. A. 1997. On crack susceptibility in the submerged arc welding of medium-carbon steel plates. Journal of Material Processing Technology 68(1): 43-49.

8. Nelson, T. W., Lippold, J. C., Lin, W., and Baeslack III, W. A. 1997. Evaluation of the circular patch test for assessing weld solidification cracking, Part I — Development of a test method. Welding Journal 76(3): 110 -s to 119 -s.

9. Shankar, V., and Devletian, J. H. 2005. Solidification cracking in low alloy steels. Science and Technology of Welding and Joining 10: 236-243.

10. Bailey, N., and Jones, S. B. 1978.
The solidification cracking of ferritic steel during submerged arc welding. Welding Journal 57(8): 217-s to 231-s.

11. Baker, H., Okamoto, H., Henry, S., Davidson, G., Fleming, M., Kacprzak, L., Lampman, H., Scott, W. Jr., and Uhl, R. 1992. ASM Handbook, Vol. 3, Alloy Phase Diagrams, 0-87170-381-5. ASM International, Materials Park, Ohio.

12. Lancaster, J. F. 1999. Metallurgy of Welding, $6^{\text {th }}$ Ed. Abington Publishing, Cambridge, England.

13. Senda, T., Matsuda, F., Nakagawa, H., Watanabe, K., and Matsusaka, T. 1974 Sulphide and its effect on solidification cracking in weld metal of steel (Report 7). J. Jpn. Weld. Soc. 43: 57-65 (in Japanese).

14. Fredriksson, H., and Stjerndahl, J. 1982. Solidification of iron-base alloys. Material Science 16: 575-585.

15. Shibata, H., Arai, Y., Suzuki, M., and Emi, T. 2000. Kinetics of peritectic reaction and transformation in $\mathrm{Fe}-\mathrm{C}$ alloys. Metallurgical and Materials Transaction B 31B: 981-991.

16. Phelan, D., and Li, H. 2016. K-TIG welding of peritectic steels. Proceedings of the 69th IIW Annual Assembly and International Conference, Melbourne, Australia.

17. Matsuura, K., Ito, Y., and Matsubara, K. 1998. Effects of composition and cooling rate on the solidification temperature range of carbon steel. Bulletin of Faculty of Engineering, Hokkaido University, No. 143, pp. 1-12 (in Japanese).

18. Vogel, R., and Hotop, W. 1937/ 1938. The phase diagram of the iron-iron sulphide-manganese sulphide manganese system (in German). Archiv für das Eisenhüttenwesen 11: 41-54. 